\title{
O conceito de estruturas celulares na concepção dos alunos do 8음 ano de Colmeia/TO
}

A Biologia Celular é um conteúdo básico para o estudo dos processos vitais e das diferentes formas de vida, sendo exigida em diversos níveis de ensino Fundamental, Médio e Superior. Dessa forma, o presente trabalho tem por objetivo mensurar o grau de conhecimento dos discentes do 8o ano da rede estadual do ensino fundamental, no Município de Colmeia/TO, a respeito de estruturas celulares, com intuito de avaliar o processo de ensinoaprendizagem nesse local. Utilizou-se como instrumento de pesquisa um questionário com perguntas objetivas, para que os alunos pudessem escolher uma das opções apresentadas, e perguntas subjetivas para que os mesmos expressassem sua concepção a respeito do assunto. Sendo baseado no Referencial Curricular do Estado do Tocantins e os Parâmetros Curriculares Nacionais de Ciências. De acordo com os resultados obtidos, percebe-se que há um índice insatisfatório de conhecimento acerca do conteúdo de estrutura celular nas escolas mencionadas, cujo os discentes apresentam dificuldade em associar os conceitos anteriormente estudados em sala de aula com as questões indagadas na pesquisa. Dessa forma, percebe-se a necessidade de o professor trabalhar teoria e prática, mostrando aos alunos a relevância dos conteúdos abordados no cotidiano, além de as escolas participantes da coleta de dados elaborarem atividades que possibilitem aos educandos uma aprendizagem significativa do tema em destaque.

Palavras-chave: Citologia; Ensino-aprendizagem; Escolas públicas.

\section{The concept of cellular structures in the conception of the students of the 8th year of Colmeia/TO}

Cellular Biology is a basic content for the study of the vital processes and the different forms of life, being required in several levels of education Fundamental, Middle and Superior. Thus, the present study aims to measure the level of knowledge of the 8th grade students of the state primary education network, in the municipality of Colmeia/TO, regarding cellular structures, in order to evaluate the teaching-learning process in this area. local. A questionnaire with objective questions was used as a research tool, so that the students could choose one of the presented options, and subjective questions to express their conception about the subject. Being based on the Curricular Reference of the State of Tocantins and the National Curricular Parameters of Sciences. According to the results obtained, there is an unsatisfactory index of knowledge about the cellular structure content in the mentioned schools, whose students find it difficult to associate the concepts previously studied in the classroom with the questions asked in the research. In this way, the teacher's need to work on theory and practice is shown, showing students the relevance of the contents addressed in daily life, and the schools participating in the data collection to elaborate activities that enable students to learn a meaningful theme.

Keywords: Cytology; Teaching-learning; Public schools.

Reviewed anonymously in the process of blind peer

Flávia Carolina Azevedo Maciel

Faculdade Guaraí, Brasil

http://lattes.cnpq.br/6896023968699001

flaviaazevedomaciel@gmail.com

Maria Goreti de Oliveira da Silva

Faculdade Guaraí, Brasil

http://lattes.cnpq.br/4391701731831457

goreth Maria2013@hotmail.com

\section{Welton Cardoso}

Faculdade Guaraí, Brasil

http://lattes.cnpq.br/9983641622413426 welton_cardoso26@hotmail.com
Mateus dos Santos Silva

Faculdade Guaraí, Brasil

http://lattes.cnpq.br/7629359984769327

mateussant563@gmail.com

Romeu Takahagassi

Faculdade Guaraí, Brasil

http://lattes.cnpq.br/4208934411077437

romeumt33@gmail.com

Anamar Campos Soares

Faculdade Guaraí, Brasil

http://lattes.cnpq.br/8747716552516844

anamarcampossoares@gmail.com
Ana Paula Martins Guimarães

Universidade Federal do Tocantins, Brasil http://lattes.cnpq.br/5309168123830683 biologa.apmg@gmail.com

Referencing this:

CARDOSO, W.; GUIMARÃES, A. P. M.; MACIEL, F. C. A.; SILVA, M. G. O.; SILVA, M. S.; SOARES, A. C.; TAKAHAGASSI, R.. O conceito de estruturas celulares na concepção dos alunos do 80 ano de Colmeia/TO. Educationis, v.5, n.2, p.6-14, 2017. DOI:

DOI: 10.6008/SPC2318-3047.2017.002.0001 http://doi.org/10.6008/SPC2318-3047.2017.002.0001 


\section{INTRODUÇÃO}

Citologia é o ramo da ciência que estuda as células e suas funções em todos os níveis de seres vivos (JUNQUEIRA et al., 2012). Dessa forma, o conhecimento dos elementos e funcionamento celular possibilita a compreensão do próprio ser humano (TEIXEIRA, 2008), contribuindo para as áreas da saúde, meio ambiente e tecnologia. No entanto, os discentes têm pouca ou quase nenhuma associação do assunto com outras áreas em seu cotidiano, sendo a célula um conteúdo complexo e distante da realidade (NASCIMENTO, 2016). Na maioria dos casos, as escolas públicas não têm estruturas adequadas para o ensino de Ciências, o que, para Nascimento (2016), contribui para que os conteúdos de Biologia Celular sejam idealizados pelos alunos de forma abstrata.

Nesse contexto, os alunos não atribuem significados aos termos técnicos que lhes são apresentados, e apenas os memorizam (VIECHENESKI et al., 2012). Para Caurio (2011), a falta de relação dos conceitos científicos com o cotidiano prejudica a compreensão desse assunto. A apresentação de respostas prontas contribui para que os conteúdos estudados na escola sejam apenas decorados "para a prova" e os alunos não alcancem uma aprendizagem significativa (TEIXEIRA et al., 2006).

Conforme afirma Pimenta (1997), a função do professor de Ciências não é apenas repassar informações, mas atribuir significados aos conteúdos, de forma que os relacione com a realidade dos educandos. Os PCNs da disciplina de Ciências da segunda etapa do ensino fundamental reforçam essa ideia, afirmando que os alunos do 8 o ano devem compreender a célula como estrutura funcional do ser vivo que formam os tecidos, órgãos, sistemas e o organismo (BRASIL, 1998).

Segundo Giordan et al. (1996), os estudantes da educação básica apresentam um nível de conhecimento insatisfatório a respeito de biologia celular, sendo que a definição de célula é confundida com molécula, átomos e tecidos. Na escola, os conteúdos científicos são muitas vezes trabalhados de maneira que o aluno pouco os compreende, o que resulta no rápido esquecimento do que foi estudado, e as ideias de senso comum percorrem até o ensino superior (MORTIMER, 1996).

O presente trabalho tem por objetivo expressar os resultados de pesquisa que avaliou o conhecimento prévio dos discentes do $8^{\circ}$ ano da Rede Estadual do município de Colmeia/TO, a respeito de Biologia Celular, abordando a célula e suas características, resultados estes obtidos através de um questionário, com intuito de diagnosticar a real situação desses alunos e trazer o olhar docente para seus métodos de ensino deste tema que é de fundamental importância para compreensão dos demais conteúdos na disciplina de Ciências e Biologia.

\section{METODOLOGIA}

O Município de estudo está situado entre as coordenadas $08^{\circ} 43^{\prime} 46^{\prime \prime} \mathrm{S}$ e $48^{\circ} 45^{\prime} 53^{\prime \prime} \mathrm{O}$, referente ao Município de Colmeia, na região norte do Tocantins, localizado a $237 \mathrm{~km}$ da capital (Palmas) e $1.087 \mathrm{~km}$ de Brasília. Possui 990,723 km² de unidade territorial, 8.611 habitantes e está sob o domínio do Cerrado (IBGE, 
2010). Nessa localidade há duas unidades escolares estaduais que abrangem o ensino fundamental II, sendo elas o Colégio Estadual Serra das Cordilheiras e Escola Estadual Ary Ribeiro Valadão Filho.

Foi realizado um levantamento de dados através de um questionário aplicado nos dias 19 e 20 de outubro de 2017, no Colégio Estadual Serra das Cordilheiras (CESC) e na Escola Estadual Ary Ribeiro Valadão Filho (ARY), mediante o Termo de Consentimento Livre e Esclarecido. Ambas as escolas estão situadas no Município de Colmeia/TO. A pesquisa envolveu 105 alunos, e seguiu as recomendações, com adaptações, de Gil (2002), o qual foi o primeiro a utilizar o questionário como instrumento de pesquisa para mensurar o grau de conhecimento a respeito de um tema específico. Fez-se uso também da pesquisa bibliográfica exploratória, que permite uma nova abordagem do assunto, propondo novas considerações (MARCONI et al., 2011).

O público-alvo foram os alunos da rede de ensino estadual do 8 o ano, em virtude de haver, na grade curricular desta turma, a apresentação dos conteúdos a respeito de Biologia Celular para a conclusão da segunda etapa do ensino fundamental, os quais serão requisitos para inicialização do ensino médio, e exigidos em processos seletivos para os cursos futuros.

O questionário proposto foi elaborado contendo 10 perguntas, abordando o conceito de célula, os diferentes tipos celulares e seus componentes em todos os níveis de organização dos seres vivos, conforme o referencial curricular do 8 o ano referente ao estado do Tocantins (TOCANTINS, 2008). Optou-se por 4 perguntas abertas, para que o aluno pudesse buscar significados e construir sua própria ideia (HOLANDA, 2002) e 6 perguntas fechadas dando a opção de múltipla escolha, o que permite designar diversas características de uma mesma temática (MARCONI et al., 2011).

Foi disponibilizada uma aula de 50 minutos de duração para resolução das questões em cada turma, totalizando 5 aulas nas duas escolas, nos períodos matutinos e vespertinos, e em um segundo momento, o material foi corrigido e a análise de dados foi feita através de estatística descritiva e quantitativa para as questões objetivas e análise fenomenológica de caráter qualitativo para as questões subjetivas (BICUDO, 2000).

\section{RESULTADOS E DISCUSSÃO}

As respostas das questões subjetivas foram classificadas em "Sabe Bem", "Sabe Pouco", "Não Sabe" e "Em Branco". Dessa forma, o primeiro quesito do questionário, de caráter subjetivo, indagou a definição de célula. As respostas podem ser analisadas na Figura 1. Conforme os dados apresentados abaixo, nota-se que dos 28 discentes do $8^{\circ}$ ano A do Colégio Estadual Serra Das Cordilheiras: 25\% ( 7 alunos) sabem bem a definição de célula; 32,14\% (9 alunos) sabem pouco; 32, 14\% não sabem; e 10,72 \% (3 alunos) deixaram em branco. Entre os 18 alunos do 8 ㅇ ano B: 22,22\% (4 alunos) sabem bem; 27, 78\% (5 alunos) sabem pouco; 27 , 78\% não sabem; e 22, 22\% (4 alunos) deixaram em branco. Já na Escola Estadual Ary Ribeiro Valadão Filho, dos 23 alunos do 8 ano 1: 21, 74\% (5 alunos) sabem bem; $34,78 \%$ ( 8 alunos) sabem pouco; $26,09 \%$ ( 6 alunos) não sabem; e 17, 39\% (4 alunos) deixaram em branco. No 8ㅇ ano 2, dos 24 alunos: 16, 67\% (4 alunos) sabem 
bem; 50\% (12 alunos) sabem pouco; 33,33\% (8 alunos) não sabem. Já no 8o ano 3, entre os 12 alunos: 41,67\% (5 alunos) sabe bem; 25\% (3 alunos) não sabem; e 33,33\% (4 alunos) deixaram em branco.

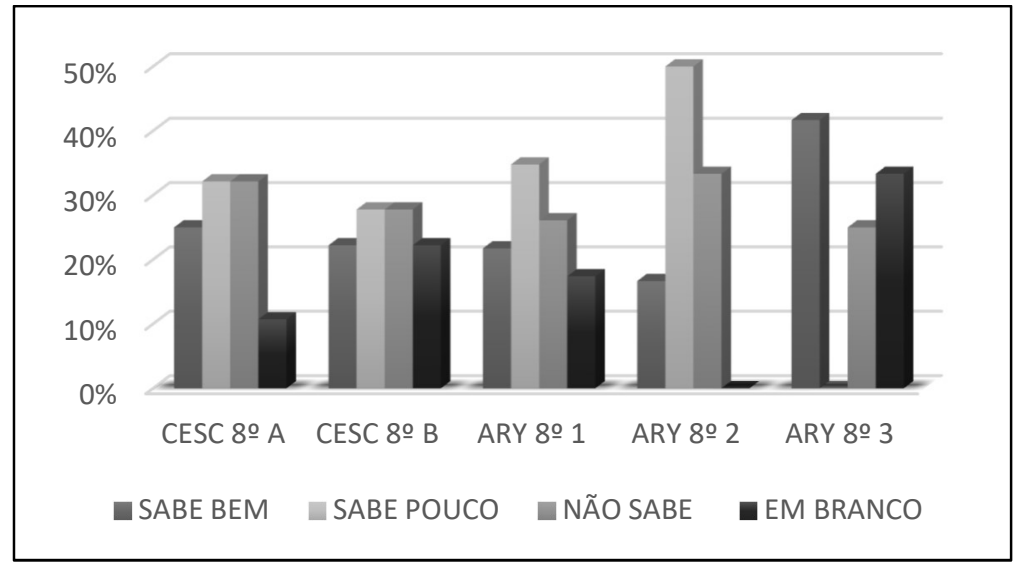

Figura 1: Expressão dos resultados das questões subjetivas que constaram no questionário aplicado aos alunos das duas escolas trabalhadas em Colmeia/TO.

Segundo a concepção dos discentes o conceito de célula é: "Todo ser vivo tem células, as células se juntam e formam tecidos" (Aluno 26, 8o ano A); "São estruturas formadas por membrana plasmática, parede celular, material genético e núcleo" (Aluno 20, 8o A); "São estruturas funcionais de um organismo vivo" (Aluno 8, 8o ano 3); "É um conjunto de bactérias" (Aluno 22, 8ㅇ ano A). A 2ㅇ questão subjetiva abordou o tipo celular do organismo humano, e diante da figura 2 abaixo, observa-se que dos 28 discentes do $8^{\circ}$ ano A do Colégio Estadual Serra Das Cordilheiras, 14,28\% (4 alunos) sabem bem que o corpo humano é formado por células eucarionte animal; 17,86\% (5 alunos) sabem pouco; 64,28\% (18 alunos) não sabem; e 3,58\% (1 aluno) deixou em branco. No entanto, dos 18 alunos do 8 o ano B: 22,22\% (4 alunos) sabem bem; $72,22 \%$ (13 alunos) não sabem; e 5,56\% (1 aluno) deixou em branco. Já na Escola Estadual Ary Ribeiro Valadão Filho, dos 23 alunos do 8 ano 1: 30,43\% (7 alunos) sabem bem; 8,71\% (2 alunos) sabem pouco; 30,43\% (7 alunos) não sabem; e 30,43\% deixaram em branco. No 8o ano 2, dos 24 alunos: 25\% (6 alunos) sabem bem; 70,83\% (17 alunos) não sabem; e 4,17\% (1 aluno) deixou em branco. Já no 80 ano 3, entre os 12 alunos: 33,33\% (4 alunos) sabe bem; $66,67 \%$ (8 alunos) não sabem.

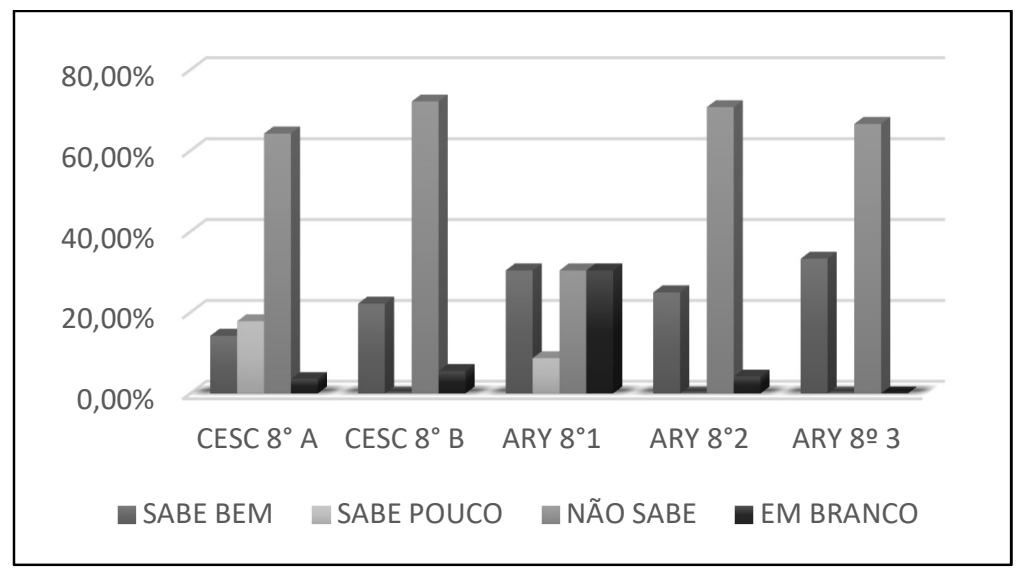

Figura 2: Expressão dos resultados das questões subjetivas que constaram no questionário aplicado aos alunos das duas escolas trabalhadas em Colmeia/TO. 
Mediante os dados descritos na figura 3, referindo-se aos mesmos conceitos predispostos anteriormente, isto é, no que tange à diferenciação conceitual do que vem a ser uma célula e suas aplicações corporais no ser humano, nota-se que dos 28 discentes do $8^{\circ}$ ano A do Colégio Estadual Serra Das Cordilheiras, $28,57 \%$ ( 8 alunos) sabem bem a diferença de seres unicelulares e pluricelulares; $25 \%$ ( 7 alunos) sabem pouco; $35,71 \%$ (10 alunos) não sabem; e 10,72\% (3 alunos) deixaram em branco; entretanto, entre os 18 alunos do 8 ㅇ ano B: $11,11 \%$ ( 2 alunos) sabem bem; $16,67 \%$ ( 3 alunos) sabem pouco; $50 \%$ (9 alunos) não sabem; e 22,22\% (4 alunos) deixaram em branco. Já na Escola Estadual Ary Ribeiro Valadão Filho, dos 23 alunos do 8o ano 1: 52,17\% (12 alunos) sabem pouco; 30,43\% (7 alunos) não sabem; 17,40\% (4 alunos) deixaram em branco. No 8 ano 2, dos 24 alunos: 16,66\% (4 alunos) sabem bem; 29,17\% (7 alunos) sabem pouco; 29,17\% (7 alunos) não sabem; e 25\% (6 alunos) deixaram em branco. Já no 8 o ano 3, entre os 12 alunos: 41,66\% ( 5 alunos) sabe bem; $25 \%$ ( 3 alunos) sabem pouco; $16,67 \%$ ( 2 alunos) não sabem; e 16,67 \% (2 alunos) deixaram em branco.

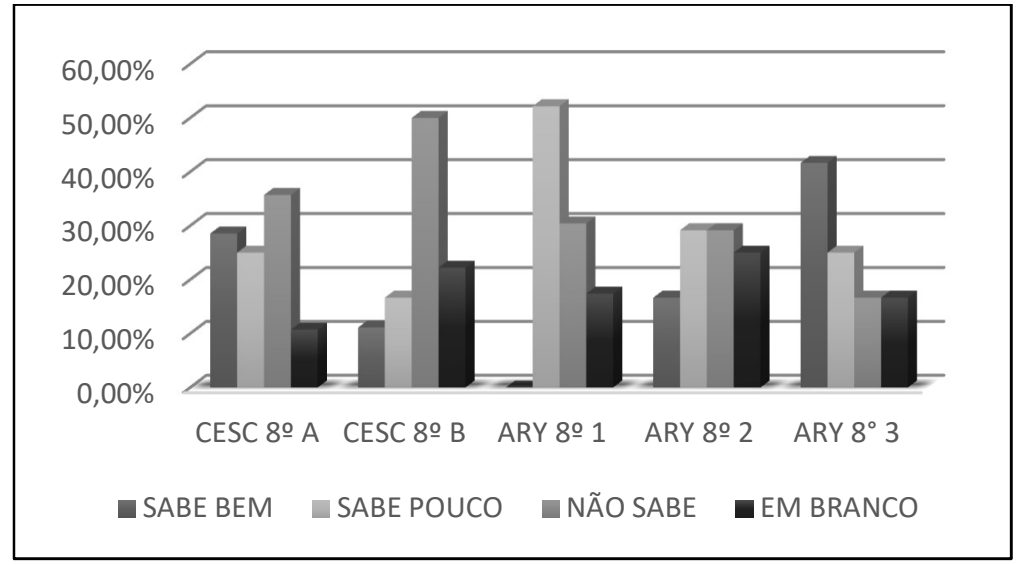

Figura 3: Expressão dos resultados das questões subjetivas que constaram no questionário aplicado aos alunos das duas escolas trabalhadas em Colmeia/TO.

Com base nos dados da figura 4, e ainda se referindo a uma proposição conceitual, isto é, aquilo que os alunos entendem por conceito de uma determinada hipótese já tendente, fez-se uma análise, e se notou, de acordo com os dados apresentados abaixo que, dos 28 discentes do $8^{\circ}$ ano A do Colégio Estadual Serra Das Cordilheiras: 78,57\% (22 alunos) sabem bem o tipo celular das bactérias; 17,86\% (5 alunos) não sabem; e 3,57 \% ( 1 aluno) deixou em branco. Referindo-se aos 18 alunos do 80 ano B: 77,78\% (14 alunos) sabem bem; 16,67\% (3 alunos) não sabem; e 5,55\% (1 aluno) deixou em branco. Já na Escola Estadual Ary Ribeiro Valadão Filho, dos 23 alunos do 8o ano 1: 65,22\% (15 alunos) sabem bem; 4,35\% (1 aluno) sabe pouco; 17,39\% (4 alunos) não sabem; e 13,04\% (3 alunos) deixaram em branco. No 8o ano 2, dos 24 alunos: 70,83 \% (17 alunos) sabem bem; 17\% (4 alunos) sabem pouco; 8,33\% ( 2 alunos) não sabem; e 4,17\% (1 aluno) deixou em branco. Já no 8o ano 3, entre os 12 alunos: 75\% (9 alunos) sabe bem; 16,67\% (2 alunos) não sabem; e 8,33\% (1 aluno) deixou em branco.

No entanto, em se tratando das questões objetivas, foram apresentadas de 4 a 5 opções de múltipla escolha, e essas foram classificadas como corretas, erradas e em branco, ou seja, não se foi proposto um "meio termo" para o aluno, trabalhando-se com objetividade. Os dados podem ser analisados nas figuras de 5 a 9. 


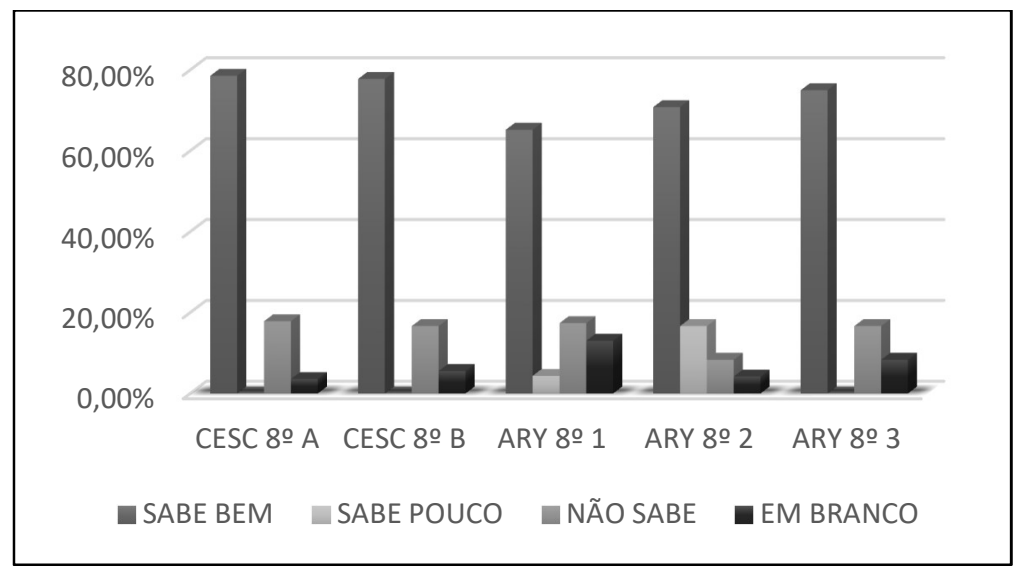

Figura 4. Expressão dos resultados das questões subjetivas que constaram no questionário aplicado aos alunos das duas escolas trabalhadas em Colmeia/TO.

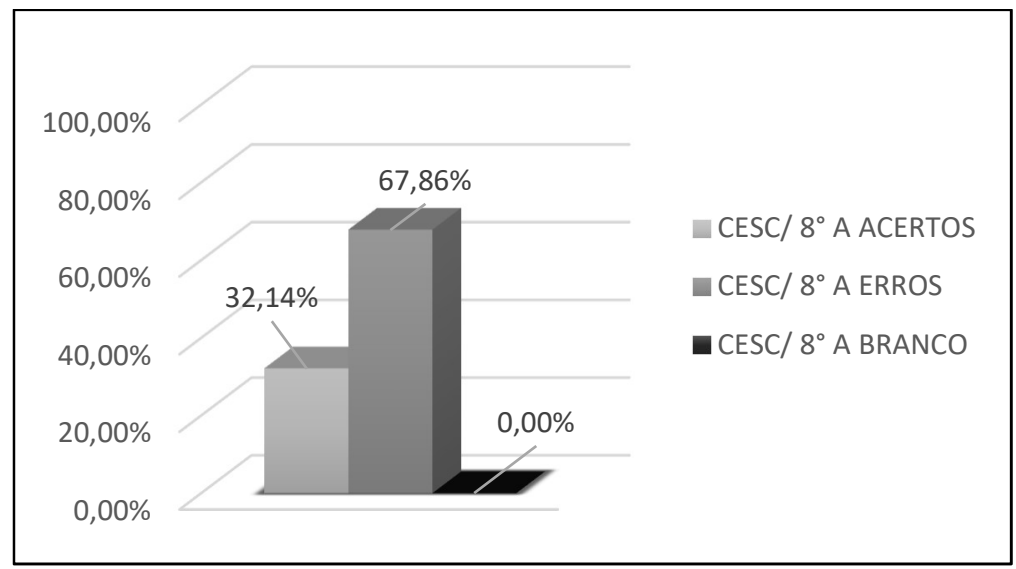

Figura 5: Expressão dos resultados das questões objetivas que constaram no questionário aplicado aos alunos das duas escolas trabalhadas em Colmeia/TO.

Na figura 5, de acordo com a representação ilustrativa propensa abaixo no gráfico, observa-se que os 28 alunos do 8 ano A do Colégio Estadual Serra das Cordilheiras alcançaram 32,14\% de acertos e 67,86\% de erros, tendo uma média de 1,9 questão correta e 4,07 questões erradas por aluno.

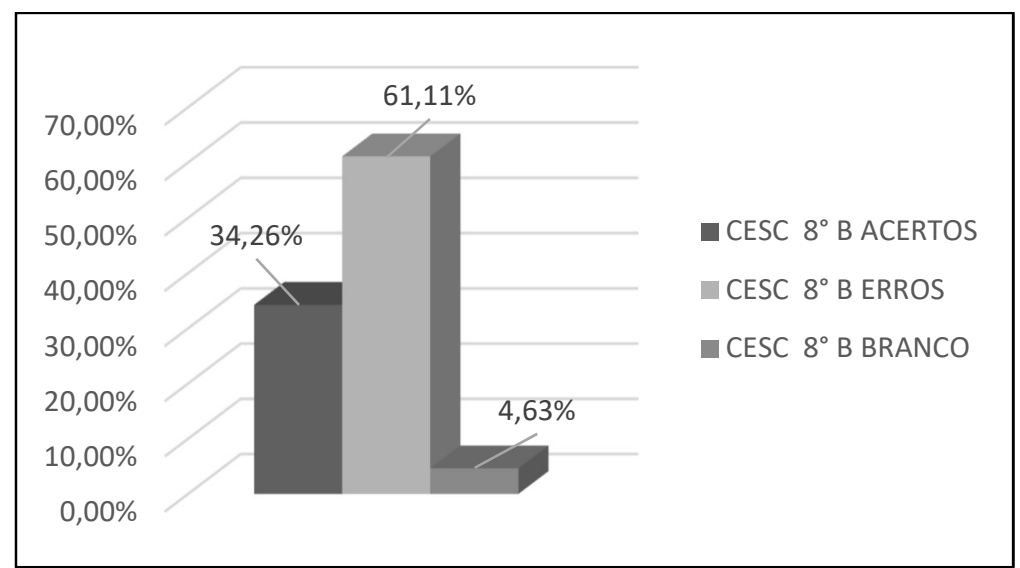

Figura 6: Expressão dos resultados das questões objetivas que constaram no questionário aplicado aos alunos das duas escolas trabalhadas em Colmeia/TO.

De acordo com a figura 6, os 18 alunos do 8 o ano B do Colégio Estadual Serra das Cordilheiras obtiveram $34,26 \%$ de acertos e $61,11 \%$ de erros, sendo que $4,63 \%$ das questões foram deixadas em branco. 
Dessa forma, apresentou-se uma média de 2,05 questões corretas e 3,66 questões erradas por cada estudante.



Figura 7. Expressão dos resultados das questões objetivas que constaram no questionário aplicado aos alunos das duas escolas trabalhadas em Colmeia/TO.

Consoante à figura 7, os 23 alunos do 80 ano 1, da Escola Estadual Ary Ribeiro Valadão Filho, conseguiram acertar $31,88 \%$ das questões objetivas, com $66,67 \%$ de erros e $1,45 \%$ em branco, ou seja, houve a omissão na marcação das respostas. A média de acertos e erros da turma foi de 1,91 por assertiva em 4 perguntas, respectivamente.

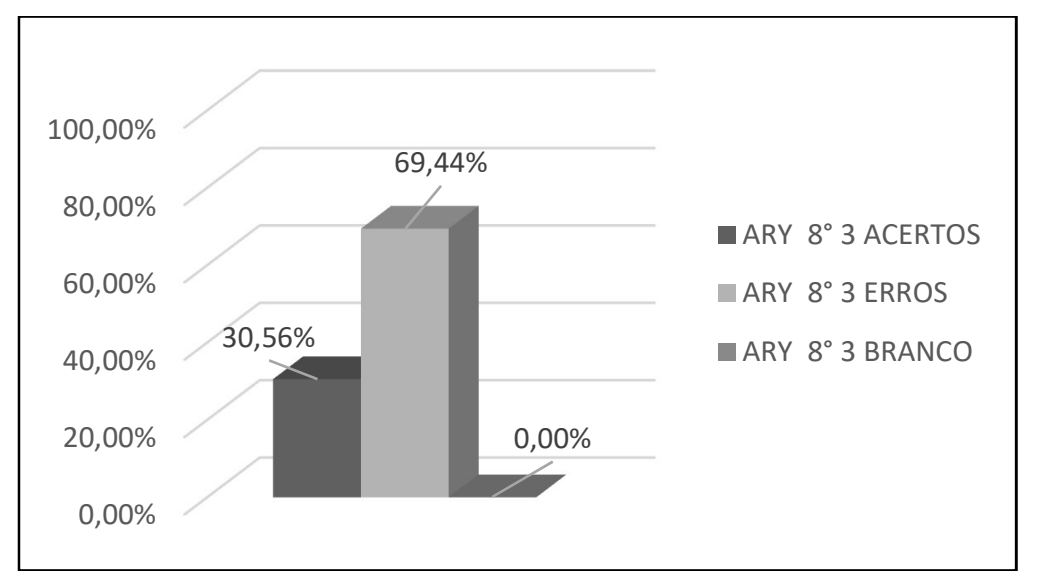

Figura 8: Expressão dos resultados das questões subjetivas que constaram no questionário aplicado aos alunos das duas escolas trabalhadas em Colmeia/TO.

O percentual descrito na figura 8 demonstra que a turma do 8 ano 3 da Escola Estadual Ary Ribeiro Valadão Filho, composta por 12 alunos, apresentou 30,56\% de acertos e 69,44\% de erros das questões objetivas, totalizando uma média de 1,83 alternativa correta e 4,17 erradas, por cada discente. Diante dos resultados expressados pelos alunos, percebe-se um índice insatisfatório acerca de células e suas estruturas, bem como a diferença de célula animal, vegetal e procarionte, e os seres compostos por cada uma destas. A única questão que apresentou 70\% (média mínima da rede pública) de acertos na maioria das turmas, foi a representação das células das bactérias por meio de desenho, embora os alunos saibam desenhar a célula procarionte, alguns a definem como eucarionte. 
Além disso, parte dos discentes acreditam que o corpo humano é formado por célula vegetal ou procarionte. Portanto, é nítida a carência do processo de ensino-aprendizagem do conteúdo abordado e a dificuldade de compreender os conceitos científicos e associá-los à realidade. Segundo os resultados obtidos por Lima et al., (2016), dentre os fatores que complicam a aprendizagem de Ciências, está a linguagem de difícil compreensão apresentada nos livros didáticos, a maneira abordada pelo professor ou ainda a falta de estrutura nas escolas públicas.

De acordo com a pesquisa de Tomaz Junior et al. (2006) com estudantes do ensino médio, é grande a dificuldade desses alunos em compreenderem conteúdos de biologia celular, como definir o que é célula e relacionar palavras a esse termo, formar a sequência correta de organização de um organismo e diferenciar os processos de mitose e meiose, por exemplo.

Um trabalho realizado por Guimarães et al. (2016) intitulado "Levantamento do conhecimento dos alunos de uma escola Municipal de Palmas - TO, sobre doenças infecciosas e contagiosas", perceberam que os alunos desta unidade escolar compreendiam bem conceitos sobre doenças, porém, não sabiam ações fundamentais ao processo ensino aprendizagem, relacionados aos mecanismos de funcionamento do mecanismo doença e contagio, desta forma, estes resultados estão de acordo com os que foram encontrados no presente trabalho, em que, poucos alunos compreendem conceitos e os mecanismos de funcionalidade das células.

\section{CONCLUSÕES}

Diante dos resultados encontrados no presente trabalho, percebe-se que os alunos das duas escolas trabalhadas não possuem um domínio acerca da temática abordada, sendo que, este problema é um parâmetro também observado por vários autores ao avaliarem o processo de ensino-aprendizagem em várias localidades do Brasil, dando a entender que o problema pode estar associado as didáticas de ensino que são utilizadas por estes professores.

Mediante essa pesquisa, percebe-se que há necessidade dos docentes do Colégio Estadual Serra das Cordilheiras e Escola Estadual Ary Ribeiro Valadão Filho elaborarem ações didáticas que venham possibilitar que os alunos alcancem as habilidades e competências exigidas pelos Parâmetros Curriculares Nacionais contextualizando os conteúdos e relacionando teoria e prática objetivando o processo de construção do conhecimento por parte dos educandos. Portanto, os resultados evidenciados contribuirão para futuras pesquisas voltadas ao ensino de Citologia nas escolas públicas.

\section{REFERÊNCIAS}

BERTOLIN, A. O.; GUIMARÃES, A. P. M.. Levantamento do conhecimento dos alunos de uma escola Municipal de Palmas - TO, sobre doenças infecciosas e contagiosas. Revista Help, Rio de Janeiro, v.2, n.1, 2016.
BICUDO, M. A.. Fenomenologia: confrontos e avanços. São Paulo: Cortez, 2000.

CARLETTO, M. R.; LORENZETTI, L.; VIECHENESKI, J. P.. Desafios e práticas para o ensino de ciências e alfabetização científica nos anos iniciais do ensino 
fundamental. Atos de Pesquisa em Educação, v.7, n. 3, p.853-876. 2012.

CAURIO, M. S. O livro didático de Biologia e a temática Citologia. Dissertação (Mestrado em Educação em Ciências) - Universidade Federal do Rio Grande, Rio Grande, 2011.

FAVETTA, L. R. A.; LIMA, B. A.; TEIXEIRA, J. M.. O conceito de célula investigado numa sala de aula de Ensino Médio: um Estudo de Caso. In: SIMPÓSIO DE ENSINO DE GRADUAÇÃO, 4. Anais. Piracicaba, 2006.

GIORDAN, A.; Vecchi, G.. As origens do saber: das concepções dos aprendentes aos conceitos científicos. 2 ed. Porto Alegre: Artes Médicas, 1996.

GOMES, R. F.; LIMA, R. C. S.; MARTINHO, M.; PRADO, R. V.. A Disciplina de Ciências na concepção dos alunos do 9o ano da Escola Municipal Silvestre Fernandes Rocha, em Zé Doca (MA). In: CONGRESSO NACIONAL DE EDUCAÇÃO, 3. Anais. Natal: CONEDU, 2016.

HOLANDA, A.. O resgate da fenomenologia de Husserl e a pesquisa em psicologia. Tese (Doutorado) Pontifícia Universidade Católica de Campinas, São Paulo, 2002.

JUNQUEIRA, L. C.; CARNEIRO, J.. Biologia celular e molecular. 9 ed. Rio de Janeiro: Guanabara Koogan, 2012.
KLEIN, T. A. S.; TOMAZ JUNIOR, O. P.. Concepções sobre biologia celular de alunos de ensino médio da cidade de Londrina-PR. Monografia (Bacharelado em Ciências Biológicas) - Universidade Estadual de Londrina, 2003.

MARCONI; M. A.; LAKATOS, E. M.. Técnicas de pesquisa: planejamento e execução de pesquisas, amostragens e técnicas de pesquisas, elaboração, análise e interpretação de dados. 6 ed. São Paulo: Atlas, 2007.

MORTIMER, E. F.. Construtivismo, mudança conceitual e ensino de Ciências: para onde vamos?. Investigações em Ensino de Ciências, v.1, n.1, 1996.

NASCIMENTO J. V.. Citologia no ensino fundamental: dificuldade e possibilidade na produção de saberes docentes. Dissertação (Mestrado em Ensino na Educação Básica) - Universidade Federal do Espírito Santo, São Mateus, 2016.

TEIXEIRA, M. C. F.. A célula: unidade na constituição dos seres vivos. Dissertação (Mestrado em Matemática e Ciências da Natureza) - Universidade de Trás-Os-Montes e Alto Douro, Vila Real, 2008.

TOCANTINS. Referencial Curricular do Ensino Fundamental das escolas públicas do Estado do Tocantins: Ensino Fundamental do 10 ao 9o ano. 2 ed. Tocantins, 2008. 